\title{
CRONOS, HIPNOS E TÂNATOS - A CONCEPÇÃO DO TEMPO E A CONCEPÇÃO HISTÓRICA NO ROMANCE $O$ BEIJO DE ESAÚ, DE MEIR SHALEV
}

Naama Silverman-Forner*

\section{Resumo}

O romance relata a história de uma família de padeiros, a família Levy: Avraham (Abrão) e Sara, os pais, e seus filhos gêmeos, Yaakov (Jacó) e Essav (Esaú). Esse artigo analisa a visão histórica refletida no romance de Meir Shalev e as tentativas de compreender a natureza do tempo. Ademais, o artigo procura definir qual é o lugar do indivíduo dentro do continuum histórico, e quais são suas relações com o tempo.

Palavras chave: Literatura Hebraica, Meir Shalev, Esaú, história

\section{Abstract}

The novel tells the story of a bakers family, the Levy family: the parents Avraham e Sara, and their twin sons, Yaakov and Essav. This article analyzes the historical vision reflected in the novel by Meir Shalev, and the attempts to understand the nature of time. Moreover, the article seeks to define the place of the individual within the historical continuum, and his relationships with time.

Keywords: Hebrew Literature, Meir Shalev, Esau, history

* Doutora em Língua Hebraica, Literatura e Cultura Judaicas pela Facudade de Filosofia, Letras e Ciências Humanas da Universidade São Paulo. <naamasf@gmail.com> 
0 tratamento relativamente extenso da temática do tempo no romance $\mathrm{O}$ beijo de Esaú - da questão de sua essência e significado e do exame da tessitura das relações entre ele e o homem - decorre, a meu ver, do desejo de entender o que permanece e o que desaparece, e se há qualquer normatividade que determine a distinção entre ambos. Nessa obra, que relata a história de algumas gerações de uma família, se oculta uma espécie de perplexidade frente a assuntos que são constantes ou que se repetem continuamente a cada geração; perplexidade que também existe em relação às coisas que desaparecem para sempre.

Dividirei as considerações sobre a concepção do tempo, do modo em que é expresso no romance, em três aspectos: o aspecto da essência do curso do tempo, o aspecto das relações entre o tempo e o espaço e o aspecto das relações entre o tempo e o homem.

O que é o tempo? Ou qual é o curso do tempo e qual é o ritmo de sua passagem? Rápido ou lento? É possível parar ou congelar o tempo? Ou identificar o exato momento de uma determinada ocorrência, como o momento em que ocorre a paixão, ou o momento da morte?

$\mathrm{O}$ primeiro aspecto analisado procura responder, ou às vezes apenas a suscitar, tais questões.

O primeiro capítulo da história central tem início em uma noite em que houve um forte terremoto em Israel, que causou grandes danos à cidade de Jerusalém ${ }^{1}$. A descrição dessa noite, das horas que antecederam o terremoto, expõe uma sensação, completa e abrangente, de grande expectativa:

Todos esperavam.

Na entrada do kishle ${ }^{2}$, o policial britânico caminhava de um lado a outro do seu posto até o final do seu turno de vigilância. $O$ padeiro anão do bairro armênio rezava para que a massa do pão crescesse. Os bilhetes no Muro das Lamentações esperavam pelo anjo com o saco

1 Em julho de 1927, houve de fato um terremoto muito forte em Israel, que causou grandes danos em Jerusalém e em outras cidades. Com relação a essa questão, bem como a outras semelhantes, Meir Shalev baseia-se em fatos históricos, porém com uma leve modificação: esse terremoto teve lugar em 11 de julho, às 16:00, e não na noite de 12 de julho, como relatado no romance. (Ver o site do Instituto Geofísico de Israel - http://www.seis.mni.gov.il/heb/last1000.html).

2 Denominação dada à prisão construída na Cidade Velha de Jerusalém no período otomano. 
de seda; as cisternas secas - pelas gotas de chuva; as caixinhas de caridade - pelo gotejar das moedas. O tempo, “o grande mestre", movia-se lentamente. Os comerciantes de antiguidades aguardavam os crédulos. As rochas cinzentas esperavam os cinzéis dos canteiros. As esposas abandonadas da Grande Guerra, o retorno e a redenção. Ao lado do Domo da Rocha circulavam os vigias mauritanos, grunhiam das profundezas do peito, exercitavam-se no estrangulamento e aguardavam pelo herege cético que ousasse subir ao Monte e profaná-lo com a secreção canina do seu hálito.

Também os mortos, “os principais habitantes da Cidade Sagrada", esperavam. (p. 28) ${ }^{3}$

O tempo, portanto, é também uma expectativa; a noite aguarda ansiosamente o seu término, assim como o novo dia prepara-se para o seu nascimento ( $\mathrm{p}$. 29). As mudanças entre o dia e a noite, assim, constituem um movimento de rotação cíclico e fixo. Elas próprias são rotineiras. E a sensação de espera que emerge da descrição ampla acima citada é uma sensação, ou uma atmosfera, de espera tensa por um evento qualquer que virá e que será capaz de quebrar essa rotina. À semelhança dos vigias mauritanos, cuja função é impedir a entrada dos hereges na área do Domo da Rocha, mas que, na verdade, aguardam com esperança ou mesmo com intenso desejo, que alguém ouse infringir a lei para que possam fazer algo que fuja da rotina; para que possam descarregar os impulsos violentos e cruéis neles retidos. Da mesma forma, toda a cidade, ou todo o universo, espera que ocorra algo excepcional, incomum, que tenha o poder de resgatar, de libertar e de enviar para os ares tudo o que gira em rotação cíclica e constante, da qual não há saída.

$\mathrm{O}$ acontecimento que "quebra tal rotina" tem lugar na mesma noite em que a história se inicia, e centra-se na personagem de Sara, que decidira tirar clandesti-

3 Todas as citações do romance foram traduzidos pela autora deste artigo. Os números das páginas se referem à versão original. 
namente sua família de Jerusalém, da cidade enclausurada, construída em pedra, para os espaços abertos da planície, para as vastas terras e os campos da aldeia. A corrida da alta e clara Sara, atrelada ao cabriolé do Patriarca como um cavalo, atravessa e corta, com sua audácia e atrevimento, a noite jerosolimita, perturbando as sequências permanentes da noite, do universo. O terremoto que ocorre naquele momento estremece montes, desmorona casas e arranca rochas - pode ser percebido como uma metáfora da força, da surpresa e da brusquidão da violação das ordens fixas, vinculadas ao abandono da cidade pela família Levi.

\begin{abstract}
Jerusalém, cujas articulações e pessoas já haviam perdido sua flexibilidade, cujos órgãos tornaramse malignos pelos tumores de pedra, cujas noites eram atormentadas por recordações de glória e dor - aguardava o grande salto, a ascensão libertadora, o agito das asas para se manter nas alturas. (p. 29)
\end{abstract}

A cidade, ou o mundo inteiro, como em um enredo de ficção, aguarda um evento excepcional, que cause uma reviravolta abrupta no curso esperado, conhecido, predeterminado. O tempo da expectativa e da espera move-se lentamente, mas no momento em que essa expectativa é atendida e ocorre algo inesperado, surpreendente e ruidoso, o tempo "começa a correr"; assim como a massa do pão, que também tem o seu próprio tempo do qual o padeiro é escravo.

Outra questão relacionada ao enigma enganoso do tempo é sua unidade menor, ou mais breve, como o ponto de marzipã - o momento decisivo no processo de preparação do marzipã da tia Dudutch, que é "[...] um fragmento fugidio do tempo que não pode ser apreendido pelos ponteiros de um relógio nem cortado por um diafragma" (p. 139). O momento preciso em que as amêndoas devem ser adicionadas ao açúcar na panela é uma fração de tempo quase que imperceptível. Não obstante a precisão requerida, apenas a experiência e a habilidade humanas podem identificá-lo, e não um instrumento de medição do tempo, como o relógio. Esse momento, como outros de sua espécie, são praticamente indefiníveis verbalmente; somente o corpo experiente os identifica de modo intuitivo, como um instinto primevo. 
O narrador assinala as tentativas de definir em palavras esse exato momento em que a calda atinge o ponto de fio correto: esse seria "o tempo curto mais longo", ou melhor, "[...] o tempo de duração de um pensamento sobre um piscar de olhos" (p. 139), para utilizar a definição do ponto de marzipã por ele preferida. As duas definições revelam a impossibilidade de definir essa unidade de tempo em palavras. A primeira, que faz uso de termos de duração de tempo, enfatiza a circularidade inescapável da própria tentativa de defini-la. A segunda suscita novas questões: o que é mais longo, o piscar de olhos em si ou o pensamento sobre ele? De qualquer modo, o que é enfatizado na verdade é nossa incapacidade de apreender algo tão elusivo.

À semelhança do ponto de marzipã, o momento da morte também é “[...] um instante inapreensível [...] porque ele passa despercebido como o reflexo de uma memória, é mais sutil que a sombra de uma pequena onda e mais breve do que uma reflexão sobre um piscar de olhos" (p. 396-397). Uma pessoa, várias vezes ao longo de sua vida, pode encontrar-se e agir no ponto de marzipã , mas apenas uma vez se encontrará a uma fração de tempo do fim da vida; e quem quiser agarrar-se a esse momento, tentar defini-lo, absorvê-lo e exauri-lo, é quem permanecerá vivo; aquele que estiver de pé junto ao leito da pessoa que passa da vida para a falta de vida. Portanto, a incapacidade de compreender esse momento de transição delicado e elusivo é equivalente à incapacidade de compreender a própria morte.

Enquanto o ponto de marzipã e o momento da morte são frações tão curtas de tempo, a ponto de dificilmente serem definíveis ou mesmo compreensíveis antes que transcorram sem volta, talvez haja situações em que seja possível parar o tempo, congelar seu movimento por um instante, ou ao menos em uma situação particular que permanecerá invariável para sempre.

Assim, por exemplo, Lea, a esposa de Jacó, que dorme na cama de seu primogênito morto, aparta-se da vida. Ela dorme o tempo todo, dia e noite, há anos. É um sono que não só a exclui do ciclo de vida, mas também a tira para fora do tempo que se move, pois "[...] Hipnos e Tânatos, os gêmeos do sono e da morte, embalavam-na nos seus braços, desaceleravam as pulsações do seu coração e vedavam-lhe os olhos" (p. 370). No mundo ao redor, o tempo passa, e as coisas mudam com ele; vidas chegam ao fim (Avraham, Sara, Binyamin), novas vidas nascem (Michael), e apenas Lea sempre dorme, na mesma situ- 
ação e no mesmo lugar. É como se por meio do sono fosse possível alcançar uma situação na qual o tempo seria suspenso, congelado, o relógio parado.

Assim também é a mosca de Efraim Brinker, embalsamada num pedaço de âmbar, ela que tem "[...] um milhão de anos de idade e está viçosa e espantada como no instante de sua morte" (p. 153). O embalsamamento, como o sono, preserva um momento eternamente, mesmo o mais evasivo deles, o da morte.

O tempo, no entanto, não pode ser interrompido, como clama Jacó. Para os pais enlutados pela morte de um filho, o tempo parece ter parado no momento em que este foi morto. $\mathrm{Na}$ verdade, suas próprias vidas ficaram presas no momento em que, para eles, foram violadas as leis mais básicas da natureza, segundo as quais a morte está associada à duração da vida, ou seja, o pai, que viveu uma vida longa, deve morrer antes do filho, que teve uma vida breve.

Se o mundo prossegue em sua periodicidade de dia e da noite, verão e inverno, é impossível impedir a passagem do tempo.

\begin{abstract}
É isso que os está matando, que tudo continue e que todas as leis estejam em vigor, que nada de fato tenha acontecido. Porque se o sol brilha de dia e a lua à noite, se chove e a massa cresce e o mundo inteiro trabalha de acordo com todas as leis - no melhor dos casos isso é um sinal de que seus filhos apodrecem nas sepulturas como seria de se esperar e, na pior das hipóteses, significa que suas pequenas mortes foram apenas parte de algo muito pior e muito maior, de uma grande trama que todos tentam compreender e ninguém consegue. (p. 263)
\end{abstract}

As várias tentativas de parar o tempo, seja pelo embalsamamento, pelo sono, ou pelo polimento diário da sepultura do filho morto, são, na verdade, tipos de manipulações humanas, tentativas desesperadas de lidar com a perda ou com aquilo que não se é capaz de compreender, como esse grande esquema da vida do qual fala Jacó. Pois se o tempo avança linearmente, ele nos aproxima cada vez mais do nosso fim. A morte, de acordo com esse entendimento, é a meta do tempo. Por outro lado, os processos cíclicos da natureza e do universo indicam 
que o decorrer do tempo é cíclico. As perguntas sobre a essência do tempo permanecem sem resposta, como transmitido no romance a partir do espelhamento da consciência de Jacó:

O tempo é um rio que tudo arrasta? Um pântano no qual nos afundamos? Talvez ele seja um bastão de corrida de revezamento, passado com grande rapidez de mão em mão? Ou talvez seja o caos primevo do qual o mundo foi criado e ao qual regressamos? (p. 370)

Outra forma de procurar entender o tempo e seu curso está expressa na tentativa de defini-lo em termos de lugar ou espaço: o tempo flui como um córrego ou um rio, e nós - seres humanos - como nos encontramos em relação a esse fluxo? "Estamos sentados nas margens do tempo ou somos carregados por seu fluxo? Ele está em nós, ou estamos nós nele?” (p. 331).

Nesse contexto, o conceito de cronotopo cunhado por Bakhtin pode propiciar um pano de fundo teórico fecundo:

"Quando Deus criou o tempo, Ele o criou em quantidade suficiente" - diz o ditado; contudo, como se sabe, a Divindade o criou de modo a fluir em uma única direção, como um vetor unidimensional. Foi isso que permitiu a Lessing argumentar que o tempo unidimensional da vida humana e o tempo linear de um texto literário se sobrepõem de modo bem sucedido. (KONSTANTINOVSKAYA, 1992, p. 131)

A percepção linear do tempo é uma das noções que Bakhtin contesta e modifica por meio do conceito de cronotopo. O rompimento da sequência cronológica no romance $O$ beijo de Esaú pode ser considerado mais uma espécie de tentativa de quebrar essa unidimensionalidade do tempo. 
A fim de apresentar a complexidade das ideias de Bakhtin, Konstantinovskaya argumenta:

É incerto se é o tempo que desliza ao longo de minha vida, emerge ocasionalmente da não existência e nela afunda novamente, ou se sou eu quem vago ao longo do tempo, do passado para o futuro, deixando o passado para trás. (KONSTANTINOVSKAYA, 1992, p. 131).

Ou seja: o tempo caminha ao lado do indivíduo ou é este quem caminha ao longo do tempo? Em outras palavras, a vida humana conduz o tempo ou é por ele conduzida? A autora apresenta um ponto de vista segundo o qual a vida encontrase em um constante estado intermediário entre essas duas opções; o significado do eterno estado intermediário é de dúvida, por um lado, e de múltiplas opções, por outro: talvez o tempo conduza e talvez seja conduzido, e talvez ambos.

A partir desse conceito, suscita-se outra questão: se o curso do nosso avanço é do passado para o futuro, isso significa que o presente inexiste e que somente há o fluxo, o movimento linear para frente?

O passado, entretanto, não é apenas o que passou e já não mais existe, afirma Konstantinovskaya (1992, p. 131); pois quando imaginamos o passado como aquilo que restou, ou que deixamos para trás, realmente criamos uma analogia entre tempo e espaço. Nessa situação, o passado ainda existe em algum lugar, porém não temos mais parte nele, e o futuro é o objetivo em direção ao qual avançamos.

Se assim for, vivenciamos o tempo medido como equivalente ao espaço, e "[...] essa sensação do tempo como essência isomórfica ao espaço gera naturalmente a imagem definida de forma retórica como uma alegoria: o mundo é uma estrada, a vida, uma jornada" (KONSTANTINOVSKAYA, 1992, p. 131). Para Bakhtin, a estrada é um dos cronotopos da cultura difundido na literatura moderna. Cronotopo é um termo por ele criado para denotar a união dos conceitos de tempo (chronos) e de espaço (topos). Esse termo é utilizado para caracterizar a estreita relação entre tempo e espaço como uma relação intrínseca que caracteriza as relações entre ambos, já que se trata de “[...] uma conexão indestrutível [...] não há tempo desconectado de lugar, e não há lugar em que não haja tempo" (BURSTEIN, 2007, p. 1). 
O próprio Bakhtin escreveu:

No cronotopo artístico-literário, indicadores espaciais e temporais fundem-se num todo compreensivo e concreto, pleno de significado. Aqui o tempo condensase, torna-se mais encorpado, comprime-se, torna-se artisticamente visível; o próprio espaço intensifica-se, penetra no movimento unificado do tempo, do enredo e da história. Os indicadores do tempo transparecem no espaço; e o espaço reveste-se de sentido em virtude do tempo e é por ele medido. (BAKHTIN 1981, p. 114)

O metaforismo que constrói o cronotopo do romance $O$ beijo de Esaú é o relacionado ao fluxo dos corpos d'água na superfície. Por conseguinte, ele pode ser denominado "o cronotopo do rio", que é semelhante ao "cronotopo da estrada" supramencionado. O cronotopo fluvial representa os dois aspectos de tempo e espaço, pois tem um curso geográfico e o fluxo d'água em seu leito possui ritmo e velocidade, ou seja, tempo.

A diferença marcante entre os dois tipos de cronotopos é que a água do rio flui ininterruptamente por si só, e a estrada não avança por si só; ela permanece estática, e é o caminhante que por ela se move, e o tempo avança ao passar por curvas e paisagens que deixa para trás. $\mathrm{O}$ rio, em contrapartida, nos deixa para trás, ou, citando Esaú: "Poderoso e indolente, o tempo deslizava, e nós, caros incrédulos, fazíamos flutuar nele os nossos barcos" (p. 347). Lançar barcos (como os barquinhos de papel da infância) sobre o rio do tempo representa uma esperança, ou uma crença inocente, pueril, de que esses barcos, que poderiam alcançar destinos incríveis, delinear ou pavimentar para nós o caminho para tais pontos de chegada. Isso é ilusório, porque os barcos navegam sem cessar e desaparecem da nossa vista e, assim, não pertencem mais ao nosso tempo. Tal era, por exemplo, a esperança, ou mesmo a pressuposição de Jacó, a de que seu primogênito, Binyamin, herdasse a padaria e continuasse o seu caminho e o de seu pai. Essa pressuposição revela-se uma ilusão brutalmente estilhaçada, não só porque o filho não queria seguir o caminho do pai, mas porque ele foi 
baleado e morreu antes do pai, contrariamente às leis da natureza. A expectativa de Jacó é uma alegoria do barquinho de papel colocado suavemente sobre a superfície da água, na crença de que chegaria a um porto seguro, mas que acabou preso, impedido de prosseguir, rasgou-se ou afundou no caminho, sem que o seu ingênuo "navegador" o soubesse.

A metáfora do tempo, que avança no espaço como um rio, é desenvolvida: "Como o Nilo, o tempo rolava no seu leito, e quando uma fossa vazia era casualmente encontrada nas margens do seu curso, apressava-se a enchê-la" (p. 379). O preenchimento de um espaço vazio com as águas do rio, como a fossa nas margens no seu curso, é uma lei da física. Qual é, no entanto, o significado do espaço vazio em termos de tempo? Talvez o vácuo do tempo sejam aquelas coisas às quais não se presta atenção; as coisas que esquecemos e sobre as quais não pensamos. O tempo, contudo, continua passando, e "faz a sua parte"; o tempo age sobre elas, e quando voltamos a discerni-las, devemos reconhecer que existe uma distância entre o que era e o que se formou sem que percebêssemos. O efeito da "fossa do tempo", que se enche, pode ser de surpresa, na melhor das hipóteses, ou de perigo, na pior. Uma ameaça que cresceu, inflou e se aproximou, sem que a vítima estivesse ciente do tempo daquela ameaça e dos seus acontecimentos. Assim são as quatro filhas de Idelman ${ }^{4}$, meninas que, de repente, tornam-se mulheres jovens, cuja semelhança entre si, sua proximidade umas das outras e o fato de sempre estarem juntas transformam-nas em uma força sedutora e perigosa. A sexualidade das meninas que cresceram constitui um grande perigo, especialmente para um solteiro recluso como Shi$\mathrm{mon}^{5}$, cuja vida seguiu continuamente no mesmo curso, sempre a mesma: a deficiência, a força física, a irrestrita lealdade para com Jacó, o mutismo e a timidez são suas qualidades desde que chegou à aldeia quando bebê.

O "vazio do tempo", nesse contexto, é criado ao lado da rotina de vida de Shimon, inconsciente de sua masculinidade e de sua sexualidade contida, cerrado em sua lealdade permanente. Tudo isso o transforma em uma vítima ideal para as quatro jovens, que derivam intenso prazer do poder que têm de desviá-lo do percurso regular e de emocioná-lo a ponto de perder os sentidos e esquecer-se das suas obrigações para com Michael, já que a casa de Jacó fora a ele confiada. 
A ideia antes abordada, de que o sono e a morte têm um aspecto de parada e congelamento do tempo, é representada pela metáfora do rio: "A mulher estava deitada no quarto do filho morto. As ondas do tempo lambiam as beiradas da cama, o seu corpo respirava e derramava lágrimas e acumulava e relaxava" ( $p$. 380). De acordo com essa frase, o sono não congela completamente o tempo, apenas o torna lento. Apesar do sono, ocorrem processos, físicos e emocionais no corpo adormecido e inconsciente de Lea. A cama balança suavemente sobre as ondas do tempo. Ela não navega, não avança para lugar nenhum, pois o seu tempo é uniforme: o mesmo local e a mesma ação. Assim, como demonstra Bakhtin, a falta de qualquer alteração no espaço e a falta de ação nesse mesmo espaço, aproxima-se do cancelamento da dimensão do tempo.

No fim dos dias "a terra e o tempo" encontrar-se-ão (p. 29), ou seja, quando ocorrer a ressurreição, e chegarmos a um mundo em que não há mais guerras $\mathrm{e}$ conflitos, tempo e espaço unir-se-ão, porque no mesmo espaço caminharão os filhos de todas as gerações. $\mathrm{O}$ tempo de fato perderá o seu significado, transformando-se apenas em espaço. Essa visão é, contudo, ilusória, "um horizonte fictício", ao qual se aspira a chegar, em direção ao qual se caminha incessantemente, mas que jamais será alcançado.

Existe um cronotopo distinto da narrativa em si, ou do processo de leitura? Helena Konstantinovskaya assinala que "[...] o caminho da narrativa e da leitura constitui, por assim dizer, uma espécie de metacronotopo do enredo, correspondente ao cronotopo da mesma narrativa" (KONSTANTINOVSKAYA, 1992, p. 132). Ou seja, se a vida é uma jornada, e o cronotopo é a estrada, o processo de leitura também segue a mesma jornada, ao longo da mesma estrada, ainda que nela haja cruzamentos, complicações ou falhas.

Essa definição ignora o elemento "tempo". Afinal, a duração da leitura é muito mais breve que o tempo descrito; podemos ler em questão de minutos, ou de algumas horas, acerca de eventos que perduraram por anos no mundo ficcional. Isso levanta a questão sobre o tempo das palavras - as palavras, a linguagem, têm um tempo diferente do tempo das ações? É bem evidente que o pensamento sobre um ato ou a sua descrição em palavras não tem a duração do ato em si; nesse caso, a linguagem verbal teria o seu próprio espaço? Por trás dessa pergunta se oculta a pressuposição de que a palavra tem sua própria existência; ela não é apenas uma ferramenta, ou um meio, para descrever uma 
estrada ou um rio, uma jornada ou uma navegação. Talvez as palavras em si tenham existência própria no espaço e no tempo - e, então, seria essa a essência da ficção? A jornada de regresso do Avraham, o pai do narrador Esaú, do Iraque à terra de Israel, é descrita no romance como uma viagem em palavras, ou melhor, no tempo das palavras:

Foi assim, em algumas dezenas de palavras, disse eu para mim mesmo, que o meu pai atravessou o grande deserto. Dele aprendi que a palavra é o veículo mais rápido, que nenhum obstáculo pode impedi-la, e ela é não só mais rápida que o vento ou a luz, mas também que a verdade. (p. 43)

A narrativa da jornada tem um tempo diferente do tempo da jornada em si. Mas talvez tenha também uma verdade distinta, como se depreende da citação acima, pois Esaú não acredita que a história de seu pai Avraham - o caminhante - sobre sua viagem no deserto seja totalmente verdadeira. Disso resulta que talvez essa jornada jamais tenha ocorrido; foi apenas uma história, apenas palavras... E o espaço no qual ela tem existência está na mente criadora de palavras de seu narrador.

Qual é a relação, ou o tipo de conexão, entre o tempo e o homem? "Um nome e duas datas. Tempo e homem”, diz o arqueólogo italiano Ermette Pierotti (p. 370). De acordo com essa afirmativa, a relação verdadeiramente importante entre o tempo e o homem é o tempo de vida do homem, do nascimento à morte.

O romance se refere a essa questão a partir de alguns aspectos. Um deles vê no homem, no seu corpo e vida, parte da periodicidade da natureza. Assim é Jacó, a quem

os anos passados em meio aos processos imutáveis da natureza, às leis de ferro da fermentação e do crescimento da massa, às cerimônias eternas do regresso à vida $\mathrm{e}$ 
de movimentos antigos testados, haviam-no dotado de uma rara medida de familiaridade e de compreensão do seu corpo. (p. 241)

Os processos repetitivos em virtude da força de uma regra que não deve ser modificada ensinam Jacó que o tempo o inclui em um processo abrangente, conduzindo-o à velhice como parte dessa periodicidade circular. Ele enfraquecerá, envelhecerá e deixará de existir, como seu pai, antes dele.

As pessoas participam, sem o saber, do ciclo das estações. $\mathrm{O}$ verão aquece e seca as plantas, e estas voltam a brotar e a verdejar na primavera. O mesmo se dá com os seres humanos:
A primavera punha a funcionar nos seres humanos relógios de luz e de calor [...] Todo o inverno haviam estado presos no seu corpo frio, e eis que agora se transformaram numa crisálida alegre e tépida de carne, que obedece aos ponteiros do nascer e do pôr do sol. (p. 382)

Segundo essa visão, o homem está no interior do tempo. É parte do seu movimento geral, sobre o qual não tem praticamente nenhum controle. Por outro lado, a relação entre o tempo e o homem é apresentada como uma relação de desconexão:

O tempo passou, fez o seu trabalho, e não nos deu atenção” (p. 198). E ainda:

'Disseram-me:o tempo cura todas as feridas'. Disseramme: 'o tempo cuidará delas. Então você sabe o quê? Talvez o tempo de fato cuide delas, mas não cuida de nós. $O$ tempo talvez faça o seu trabalho, mas não faz o nosso'. (p. 278) 
O tempo não cura e não enfraquece ou entorpece a dor do pai enlutado, ao contrário da promessa estereotipada de que o tempo pode curar todas as dores. As expressões que se repetem nas duas citações acima, de que o tempo faz o seu trabalho, destacam o absurdo dessa frase convencional. A função do tempo é transcorrer, avançar, seguir em frente, não curar as dores das pessoas, ou ser protelado a fim de oferecer ajuda e conforto a adolescentes apaixonados e atormentados.

De acordo com Avraham Levi, o tempo é "[...] uma sucessão inclemente de oportunidades perdidas" (p. 330). Isto é, em cada momento na vida há possibilidades latentes, mas, aparentemente só conseguimos identificá-las depois de terem passado. Talvez a criação possa retardar um pouco o tempo, que se apressa a transcorrer, talvez porque pode lhe conferir significado. É por isso que o narrador diz que o momento lhe pede para escrever, “[...] para que possa passar" (p. 330).

Nesse caso, às vezes, ou muitas vezes, na verdade, a relação entre o homem e o tempo está associada a uma sensação de estranhamento ou de oportunidade perdida; como se o tempo seguisse adiante sem tocar na pessoa, ou, alternativamente, sem que a pessoa o retardasse a fim de concretizar uma possibilidade. Às vezes, assim passa o tempo, talvez roçando de leve nossa face, porém continuamos a viver como se nada estivesse acontecendo.

O terceiro aspecto é o da simultaneidade. Um bom exemplo dessa concepção pode ser encontrado na narrativa sobre as praot $^{6}$ de 1929, em que a Miriam Ashkenazi, uma personagem paralela à tia Dudutch na trama central, num só instante, ouve, vê e se dá conta dos terríveis acontecimentos: seu marido agonizante, o bebê engatinhando na direção do pastor assassino; a respiração pesada e o hálito dos agressores e seus próprios gritos. E em meio a tudo isso, ela "[...] sabia que durante todo esse tempo os queijos continuavam a coalhar e os iogurtes a fermentar" (p. 236).

A percepção simultânea de eventos tão distintos é uma mostra da complexidade do mundo. Ela atesta uma compreensão profunda e abrangente das tramas da vida: o tempo não avança em um único trajeto, mas numa rede extensa de caminhos, estradas e enredos. E tudo ao mesmo tempo. Os massacres, os

6 Praot é o termo em hebraico para pogrom, em russo. O pogrom é uma ação violenta contra um grupo de minoria étnico ou religioso; ação que inclui danos pessoais e de propriedade. 
distúrbios sangrentos, por mais terríveis que fossem não interromperam os demais processos que se desenvolviam e que ocorriam no tempo. No entanto, pode-se ver também um traço interessante comum aos dois acontecimentos - os horrores das praot e a fermentação do leite. Ambos representam os processos que, uma vez iniciados, não há como detê-los; depois que a levedura é juntada ao leite, o processo de fermentação e de coalho prossegue por si só. E uma vez lançado o chamado à multidão inflamada, não há controle dos impulsos desenfreados? ${ }^{7}$.

A noção de que um determinado acontecimento necessariamente acarreta outros, sobre os quais ninguém tem controle, e de que não há possibilidade de recuar, mudar ou interromper a concatenação dos eventos seguintes, também caracteriza a percepção histórica do romance. Um exemplo divertido, que ilustra simbolicamente essa ideia, pode ser encontrado no episódio em que a Sara, a mãe do narrador Esaú, aperta as mãos ao redor do pescoço de um vendedor ambulante de miudezas, marido de Chenou Apari ${ }^{8}$, em resposta à afronta por ela sofrida. No momento em que Sara tira as mãos do pescoço dele, o mascate profere algumas maldições entrecortadas. Esaú, o narrador, que presenciara essa cena, indaga-se

\section{[...] se as maldições que saíram da boca do vendedor ambulante tinham sido pronunciadas naquele instante, ou se já haviam estado presas em sua garganta e só puderam sair quando mamãe lhe largou o pescoço. (p. 149)}

7 O "Manifesto da Comissão da Cidade para os Judeus de Jerusalém", publicado depois dos distúrbios, na data de 29 de $A v 5.689$ (4 de setembro de 1929) afirma: "De fato, algumas horas mais tarde, verificou-se que todas as promessas do governo eram infundadas. O próprio governo informou os membros de nossas forças que solicitaram ajuda que era impotente para deter o mal" (p. 18).

"Atacantes selvagens, organizados e armados, invadiram como um holocausto nossa cidade, de todos os lados [...] aos olhos do sol e aos olhos do governo mataram, massacraram e destruíram o trabalho cultural e criativo investido por gerações. Dezenas de jovens, velhos, mulheres e crianças foram mortos brutalmente depois de gravemente feridos [... ] por mãos cruéis, e muitos depois de torturas em que lhes arrancaram os olhos, e depois de estupros abomináveis. Um velho rabino e sua esposa foram queimados vivos. Sinagogas e rolos sagrados da Torá, profanados e queimados" (p. 19).

Este documento é citado em Amikan (1929). O livro documenta os pogroms de acordo com os jornais da época.

8 Chenou Apari, conosco em Paris, é o apelido da cabeleireira da aldeia, que costumava começar todas as suas frases com as palavras "chenou a pari". 
Nesse caso, não havia opção a não ser soltá-las da garganta e fazê-las ouvir por todos os presentes, ainda que seja provável pressupor que, após a agressão de Sara, o mascate tenha ficado assustado o suficiente para arrepender-se de cada insulto proferido contra ela.

Um aspecto adicional e interessante da visão histórica presente na obra é expresso no trecho a seguir que descreve a viagem de Avraham, da Mesopotâmia de volta à terra de Israel, no final da Primeira Guerra Mundial:

\begin{abstract}
Às vezes ouvia ao longe o uivo dos chacais do deserto e o tilintar de caravanas distantes e esses ruídos pareciamlhe próximos e muito assustadores, porque então ainda não sabia que o deserto, tal como o mar, transmite os sons por distâncias enormes. Só depois que regressou a Jerusalém e contou a Liyahu Natan sobre os ruídos que ouvira no deserto, seu amigo explicou-lhe que, devido à lentidão das ondas sonoras, ele na realidade ouvira 0 choro das harpas dos exilados da Babilônia, os passos das falanges de Alexandre, o Grande, que marchavam para a morte no Oriente. (p. 42-43)
\end{abstract}

Na verdade, a pressuposição de Avraham, segundo a qual ele ouvira o uivo dos chacais e as caravanas distantes, é muito mais razoável e realista do que a explicação dada por Liyahu Natan, o "gênio" monastiriniano". Contudo, a opção dada pelo autor implícito à explicação menos plausível é que enfatiza sua importância como instrumento para expressar uma ideia mais geral. $\mathrm{O}$ argumento que se depreende do trecho é o de que o passado não transcorre e desaparece simplesmente, porém se acumula, como se os diversos períodos históricos se empilhassem uns sobre os outros, estrato sobre estrato, e todos continuassem a existir lado a lado com o presente. "Tudo que na terra é separado pelo tempo, funde-se na eternidade na pura simultaneidade da coexistência [...] O mundo inteiro deve ser visto como simultâneo" (BAKHTIN, 1981, p. 148). 
A descrição do rei David, que, na sua tumba, aguarda a ressurreição dos mortos como os habitantes de Jerusalém esperam o sol nascer em um novo dia, ilustra a concepção do passado como parte de um presente vivo e real:

Do seu antro secreto, o rei lutava na sua cama, as suas costelas rangiam e trepidavam. Uma brisa fétida soprava nas cavernas de poeira, dedilhava a lira pendurada à sua cabeceira, pairava sobre o que restara de seus cabelos ruivos colados ao crânio, examinava o fio da sua espada de dois gumes e a superfície polida do escudo. Mas a criança que ofertaria às suas mandíbulas o frasco de água vivificante, a criança inocente, amedrontada, que colocaria a pequena palma de sua mão na mão apodrecida, tirando-o do túmulo e conduzindo-o em direção ao seu povo cheio de esperança - também ela tardava em chegar. (p. 29)

"Nada mais acontece pela primeira vez, e nada acontece uma única vez na vida" (p. 99), diz o velho Avraham Levi. Essa frase do homem que aprendeu por experiência própria, para quem a vida nada mais pode oferecer de novo e que, certamente, não pode surpreendê-lo, também representa um conceito central, que não vê na história uma sequência linear, porém um círculo sem fim, se bem que com personagens e versões diferentes. A matriosca que Sara traz consigo a Jerusalém, e com a qual presenteia Dudutch, é composta de quatro bonecas de madeira, uma dentro da outra, "[...] que têm o mesmo sorriso, os mesmos olhos e as mesmas bochechas vermelhas" (p. 71), e simboliza bem essa concepção. A história se repete como ondas, com um movimento em espiral: as mesmas personagens ou seus símiles retornam em diferentes gerações e lugares. O passado é, portanto, um reflexo do presente, e o presente, um espelho do futuro. Assim são as quatro filhas de Idelman, parecidas entre si, uma apenas um pouco menor que a outra, à semelhança das matrioscas, de modo que "[...] a pequena era a recordação da grande, e a grande, a profecia da pequena" (p. 379). 
Shimon contenta-se e gosta de fincar sua bengala exatamente no mesmo lugar por ela marcado um dia antes (p. 381). Assim ele caminha sobre as pegadas e as marcas do passado. Seu prazer deriva-se, aparentemente, do fato de que as marcas do dia anterior confirmam sua própria existência e seu lugar no mundo e no tempo. É o passado, portanto, que dá sentido à nossa existência no presente.

O movimento cíclico da história une o passado, o presente e o futuro. O versículo que Avraham Levi gosta de citar na versão ladina, "Nada de Nada que Dicho Kohelet", que nada mais é que "Vaidade das vaidades, diz o pregador [...]" (Ec 1:2), lembra outro versículo conhecido do mesmo livro: "O que foi isso é o que há de ser; e o que se fez, isso se fará; de modo que nada há de novo debaixo do sol" (Ec 1:9). Esse versículo expressa muito bem a ideia de que a história se repete, mesmo que em Eclesiastes ela seja acompanhada por um tom pessimista.

Uma noite na padaria é um ciclo completo de vida e morte: "O fermento nasce, vive, consome-se e morre como a primavera, o verão, o outono e o inverno [...]" (p. 263). O ciclo de vida da panificação repete-se todas as noites. Esse conceito une a ideia de que a história se repete a outra concepção, a de que numa sequência cronológica há um equilíbrio - um processo constante e cíclico de equilíbrio -, tais como o nascimento e a morte. "Você sabia", pergunta o narrador à sua destinatária misteriosa, como se lhe contasse uma anedota casual, “[...] que em 1927 restavam em Jerusalém apenas vinte e um caraítas ${ }^{10}$, e um deles morria no mesmo dia em que nascia um bebê?" (p. 392). A despeito da fortuidade da pergunta, ela ainda assim expõe a visão de que existe algum equilíbrio cósmico na sequência histórica; uma pessoa nasce e outra morre, assim como nasce um novo amor depois que outro fenece. O mesmo ocorre, por exemplo, quando o pai de Lea abandona sua casa e sua esposa; poucos minutos mais tarde Jacó entra nessa mesma casa e se apaixona pela filha dele.

Esaú zomba, por um lado, dos americanos que tanto anseiam pela história e que se emocionam ao encontrar utensílios antigos "[...] de duzentos e cinquenta anos" (p. 351). Na opinião de Esaú essa é uma história ridícula; história tão jovem que não

10 Ramificação do judaísmo que não aceita a Lei Oral e suas interpretações consolidadas pelos sábios talmúdicos. O caraísmo desenvolveu-se no século VIII, difundindo-se pelas diversas comunidades judaicas. Atualmente, os caraítas constituem um pequeno grupo, distribuído em algumas comunidades em Israel 
tem profundidade. Tal anseio, entretanto, atesta a necessidade humana de história, de conexão a um passado o mais longínquo e ininterrupto possível.

O mesmo narrador, por outro lado, argumenta que "[...] tende a ignorar o fato de que as pessoas são dotadas de vida e história antes que cruzem com a minha vida ou a toquem" (p. 35).

Isso mostra o contraste entre o desejo do homem de saber sua procedência, de ver a si mesmo como parte de uma longa cadeia que não se desconecta, e o de ver sua vida como tendo importância singular, uma existência única, como se o seu tempo na terra tivesse um significado próprio.

\section{Referências}

AMIKAM, Israel. Hahatkafá al Haishuv Hayehudi Beeretz Israel be 1929. Haifa, 1929. (O Ataque Contra a Comunidade Judia na Terra de Israel em 1929)

BAKHTIN, Mikhail. Forms of Time and of the Chronotope in the Novel. The Dialogic Imagination - Four Essays. United States of America: University of Texas Press, 1981.

BURSHTAIN, Dror. Zman Likrô Bakhtin. Haaretz, 18 jul. 2007. Disponível em: <www.haaretz. co.il>, p. 1-4. (Hora de ler Bakhtin)

KONSTANTINOVSKAYA, Helena. Darkey Hachronotop (Zman Vemerchav Etzel Sterne, Hertzel, Brener). Efes Shtaim, 1992, p. 131-139. (Formas do Cronotopo-Tempo e Espaço na Obra de Sterne, Hertzel, Brener)

SHALEV, Meir. Essav. Tel-Aviv: Am-Oved, 1991. (O Beijo de Esaú). 